\title{
La metafísica de la existencia humana de Gabriel Marcel
}

\author{
SEBASTIÁN KAUFMANN SALINAS \\ Universidad Alberto Hurtado (Chile) \\ skaufman@uahurtado.cl
}

\begin{abstract}
Resumen
En este artículo sostengo que Gabriel Marcel desarrolla una metafísica de la existencia humana a partir de una fenomenología. Para mostrar esta hipótesis, parto del diagnóstico que hace el autor de la situación del hombre contemporáneo. Marcel afirma que el ser humano ha sido reducido a un mero haz de funciones no dando espacio para el misterio. A partir de ese diagnóstico, desarrollo el concepto de exigencia ontológica el cual nos permite, sostengo, pasar de una fenomenología a una metafísica, desde el momento en que Marcel plantea que la exigencia ontológica no es solo una necesidad subjetiva de sentido, sino el correlato del misterio ontológico en el cual nos encontramos insertos. La filosofía del misterio del Marcel, eje central de su metafísica de la existencia humana, es explicada y explicitada en la segunda parte de este trabajo, a partir del dato de la encarnación y del problema de la participación.
\end{abstract}

Palabras claves: Marcel, problema, misterio, metafísica, encarnación, participación.

\section{The metaphisics of the buman existence of Gabriel Marcel}

\begin{abstract}
In this article, I hold that Gabriel Marcel proposes a kind of metaphysics of human existence that arises from a phenomenology. In order to show this hypothesis, I start from the description that the author does of the situation of contemporary man. Marcel affirms that human being has been reduced to a mere assembly of functions, without leaving any room to mystery. Starting from this account, I develop the concept of ontological need, concept that allows us to go from phenomenology to metaphysis, because the concept of ontological need, according to Marcel, is not only the expression of a subjective need of finding sense, but the expression of the ontological mystery in which we find ourselves. The philosophy of mystery of Marcel, backbone of his metaphysics of the human existence, is explained in the second part of this article, by giving an account of the basic fact of being an incarnated being and by discussing the problem of participation.
\end{abstract}

Key words: Marcel, problem, mystery, metaphysics, incarnation, participation.

Doctor en Filosofía. Director del Pregrado del Departamento de Filosofía de la Universidad Alberto Hurtado. Entre sus publicaciones recientes cabe mencionar los artículos "Multiculturalidad y Ética del Reconocimiento" (2011) y "Ser y Libertad. La Ética como Filosofía Primera en Gabriel Marcel” (2002). 


\section{Introducción}

«¿Se puede hablar hoy, todavía, de metafísica sin ruborizarse?», se pregunta Jesús Conill en su libro El Crepúsculo de la Metafísica. Acaso, continúa, la metafísica ¿«no ha sido desechada por la crítica, por las ciencias, por el desarrollo social, por las nuevas racionalidades teóricas y prácticas, así como por las mismas condiciones de la vida modernizada?» (Conill, 1988: 11). Pese al desprestigio de este saber, la pregunta por la posibilidad de la metafísica se mantiene siempre vigente, sobre todo tomando en cuenta la tendencia del ser humano a ir más allá de los límites de la experiencia posible, para hablar al modo kantiano, y preguntarnos por aquello que la fundamenta. Este artículo pretende responder a esta pregunta mostrando una posibilidad concreta de metafísica en un tiempo que se ha denominado post-metafísico. Me refiero a la metafísica de la existencia de Gabriel Marcel, quien, como veremos, abre la posibilidad de pensar ciertos elementos metafísicos propios de nuestra existencia. Esta metafísica si bien se aleja de toda pretensión sistemática, plantea interesantes posibilidades para profundizar en el misterio de la existencia humana.

En este artículo me propongo dos cosas. En primer lugar, mostrar cómo es posible la metafísica en Marcel, es decir, lo que se puede llamar el método filosófico que sigue el autor francés para desarrollar su metafísica. Mi tesis, a este respecto, es que Marcel a partir de una fenomenología de la existencia humana desarrolla una metafísica de la existencia bumana. En segundo lugar, pretendo esbozar algunos elementos de lo que sería una metafísica de la existencia humana en Marcel a partir de dos nociones claves en su pensamiento: la noción de ser encarnado y la noción de participación.

Para desarrollar estas tesis, partiré presentando el diagnóstico que hace Marcel de la situación del hombre contemporáneo a partir de la categoría de función. Esto nos permitirá acceder a la categoría de exigencia ontológica la cual a su vez nos llevará a la noción, ya plenamente metafísica, de misterio ontológico. Luego, presentaré la noción de ser encarnado y de participación, lo que nos permitirá esbozar, en la conclusión, algunos elementos de lo que sería la metafísica de la existencia humana de Marcel.

\section{La situación del hombre contemporáneo}

Marcel en numerosas partes de su obra nos ofrece una mirada muy concreta y lúcida de la situación del hombre contemporáneo, que al mismo tiempo contiene rasgos aplicables al hombre de todos los 
tiempos. Para abordar este tema nos centraremos en las reflexiones que hace en la obra Aproximación al misterio del ser, en la cual se nos ofrece un acercamiento muy lúcido y sistemático a la problemática del hombre actual.

La época moderna se caracteriza, según Marcel, por una desorbitación de la idea de función. Esta desorbitación no sólo afecta a la visión que tenemos de los «artefactos»o de la técnica, sino que el hombre mismo aparece como un «simple haz de funciones» (Marcel, 1987: 23). Este reduccionismo se refiere tanto a las funciones vitales como a las sociales. En el caso de las funciones vitales, los grandes responsables de que se las mire como meras funciones son el materialismo histórico y el freudismo. En cuanto a las funciones sociales, la misma sociedad se ha organizado de tal manera que funcionaliza al ser humano y lo reduce a su función de consumidor, productor, ciudadano, etc. (Marcel, 1987: 24). Las funciones psicológicas que podrían bien abrir una brecha en este panorama deshumanizador, han sido asimiladas ya a las funciones vitales, ya a las sociales (Marcel, 1987: 24).

Esta exacerbación de la idea de función, nos lleva a considerar ciertos problemas, como el problema de la natalidad o el problema de la muerte, esencialmente humanos y complejos, bajo esta óptica reductora de la funcionalización (Marcel, 1987: 26). Así nos encontramos que ni siquiera las situaciones límites (Jaspers, 2006) son capaces de sacarnos de este espiral deshumanizador al ser incluidas instintivamente bajo esta óptica de la funcionalización: «Incluso la muerte aparece aquí, desde un punto de vista objetivo y funcional, como la puesta fuera de uso, como lo inutilizable, como el desecho puro» (Marcel, 1987: 26).

Las consecuencias de este mundo donde el hombre ha sido reducido a una función para Marcel están a la vista. El primer síntoma es la «asfixiante tristeza que se desprende de un mundo cuyo eje central es la función» (Marcel, 1987: 26) y el «sordo e intolerable malestar experimentado por quien se ve reducido a vivir como si efectivamente se le confundiera con sus funciones» (Marcel, 1987: 27), todo lo cual nos lleva a un orden social cada vez más inhumano.

Para Marcel este mundo funcionalizado es un mundo vacío, que fácilmente nos podría llevar a la desesperación total de la cual nos libramos gracias a que actúan en nuestra existencia ciertos poderes secretos que el tipo de vida actual no está en «condiciones de pensar, ni de reconocer» (Marcel, 1987: 28). Estos poderes secretos, lejos de ser algún tipo de esoterismo, son aquellas corrientes vitales que confabulan para que la vida no caiga en esta desesperación y las que si tomáramos en serio podrían llenar nuestra vida (Marcel, 1987: 28). 
El vaciamiento del mundo, ligado a la total funcionalización del hombre, tiene que ver con dos categorías claves para Marcel: problema y misterio ${ }^{1}$. Este mundo funcionalizado ha reducido todo a problema, es decir, ha eliminado o ha tratado de eliminar el misterio, poniendo «en juego, en presencia de acontecimientos que rompen el curso de la existencia, como el nacimiento, el amor, la muerte..., esta categoría psicológica y pseudocientífica de lo enteramente natural» (Marcel, 1987: 28). Es decir, cada vez que el hombre se encuentra frente a acontecimientos que no son entendibles en meras categorías de funciones o que no pueden ser abarcadas por una mentalidad cientificista, en vez de abrirse a otras categorías más comprehensivas, degrada el asunto en cuestión reduciéndolo a algo «enteramente natural», incapaz de ver en él la densidad significativa que envuelve. Para Marcel, esta actitud muestra a un «racionalismo degradado, para el cual la causa explica el efecto, es decir, da cuenta de él plenamente» (Marcel, 1987: 28). Sin embargo, como es obvio, esta actitud "problematizadora» no agota las cuestiones, por lo cual hay lugar para infinitas investigaciones. Por otro lado, los problemas teóricos, que podrían eventualmente dejar un lugar al misterio, se han puesto al servicio de los problemas técnicos, como medios para resolverlos.

\section{E1 hombre frente al misterio}

Marcel ve en el hombre una posibilidad de superar la estrechez de lo problematizable para encumbrarse a regiones más profundas de la vida, es decir, para encaminarse al ámbito del misterio. Esta posibilidad de abrirse al misterio, a saber, a aquellas realidades en las que de algún modo estoy ya comprometido y que no se pueden reducir a un análisis calculador, clasificador, la denomina como la exigencia ontológica.

Podríamos decir que esta exigencia ontológica es analogable a la necesidad de sentido, a la necesidad íntima que todos tenemos de saber que, más allá de todas las apariencias contradictorias y confusas, la realidad tiene una coherencia. Incluso en los más acendrados pesimismos filosóficos, Marcel ve presente esta exigencia: «El pesimismo sólo adquiere sentido cuando dice: sería necesario que el ser fuera, pero el ser

\footnotetext{
$1 \quad \mathrm{Al}$ respecto, Marcel nos ofrece la siguiente distinción: «El problema es algo que se encuentra, que obstaculiza el camino. Se halla enteramente ante mí. En cambio, el misterio es algo en lo que me hallo comprometido, a cuya esencia pertenece, por consiguiente, el no estar enteramente ante mí. Es como si en esta zona la distinción entre en mi y ante mi perdiera su significación» (1969: 124).
} 
no es, y, por tanto, yo mismo que hago esta comprobación soy nada» (Marcel, 1987: 30).

Así vemos que la ontología de Marcel, lejos de presentarse como una cuestión teórica, se refiere a una experiencia del ser. En cuanto a lo que se refiere con la palabra ser, propone un acercamiento tipo vía negativa, diciendo lo que el ser no es: «el ser es aquello que se resiste -o sería aquello que se resistiría- a un análisis exhaustivo sobre los datos de la experiencia y que tratara de reducirlos progresivamente a elementos cada vez más desprovistos de valor intrínseco o significativo» (Marcel, 1987: 30). Es decir, para Marcel el ser es aquello que se sitúa precisamente más allá de lo problemático, más allá de ese acercamiento a la realidad propia del científico que tiende a acotar, clasificar, explicar por causas y efectos.

Como decíamos, nuestro filósofo reconoce en ciertas filosofías que niegan todo sentido, una afirmación implícita de la necesidad de ser que tenemos. Sin embargo, también reconoce la posibilidad de que una filosofía se niegue a reconocerla. Precisamente es ese el giro que ha tomado, a su juicio, el pensamiento moderno: «Es posible una filosofía que se niegue a tener en cuenta la exigencia ontológica: y justamente hacia esta abstención es hacia donde ha tendido el pensamiento moderno en su conjunto» (Marcel, 1987: 31). Esta «abstención» frente al problema ontológico aparece como un agnosticismo o más radicalmente toma la forma de un pensamiento que ve en la exigencia ontológica la expresión de un dogmatismo caduco (Marcel, 1987: 31).

\section{El misterio ontológico}

Hasta ahora nos hemos movido en un plano descriptivo, fenomenológico, que reconoce al mismo tiempo de que el mundo se ha vuelto un lugar funcionalizado que tiende a dejar en el hombre un gran vacío, la necesidad que todos tenemos de encontrar un sentido, de que la realidad sea más que un juego de apariencias. El más agnóstico y pesimista de los filósofos podría concordar con nuestro autor, pues no hemos aventurado ningún juicio metafísico. Toda esta necesidad podría ser simplemente y meramente eso: una necesidad. Ahora bien, el que esta necesidad pueda encontrar una satisfacción en otro plano, escapa ya al ámbito fenomenológico y nos lleva a consideraciones metafísicas.

Este es el salto que hace Marcel. A nuestro juicio pasa casi imperceptiblemente de una fenomenología de la necesidad ontológica a una metafísica del misterio ontológico. ¿Es un paso legítimo? Creemos que Marcel no pretende «proban» la necesidad lógica o metafísica de este paso. Simplemente aventura ciertas ideas que no quieren dirigirse a 
nosotros bajo la forma de un discurso necesario que se imponga por su propia lógica, sino bajo la forma de un discurso insinuativo que se dirige a nuestra libertad.

El misterio ontológico aparece en primer lugar como una exigencia de trascendencia, en la medida que es vivida como una insatisfacción, como la necesidad de completar algo que falta:

Es necesario que haya - o sería necesario que hubiera - ser; que no todo se reduzca a un juego de apariencias sucesivas e inconsistentes - esta última palabra es esencial- o, como diría Shakeaspeare, a una historia contada por un idiota; en este ser, en esta realidad yo aspiro ávidamente a participar de alguna manera; y quizá esta misma exigencia sea ya, en cierto grado, una participación por rudimentaria que sea (Marcel, 1987: 30).

En todo caso, el misterio ontológico no puede mirarse como una mera necesidad psicológica, sino se trata «de un impulso surgido de las profundidades que únicamente puede interpretarse como un llamado» (Marcel, 1953: 230). Por eso mismo, al ser esencialmente un llamado, no se puede reducir su cumplimiento a un «simple decreto del querer», sino que implica «la cooperación de multitud de condiciones sobre las cuales el sujeto no tiene influencia directa» (Marcel, 1953: 52).

Este misterio aparece también como una presencia o como la «realización interior de la presencia en el seno del amor que trasciende infinitamente toda verificación concebible, ya que se ejerce en el seno de un inmediato situado más allá de toda mediación pensable» (Marcel, 1987: 32). Esta presencia es también sentida como plenitud, una "plenitud que se oponga al vacío interno de un mundo funcionalizado» (Marcel, 1953: 235). Puede parecer vago u oscuro el acercamiento que hace a este asunto. Sin embargo, es absolutamente consecuente con la naturaleza de la cuestión que trata. El misterio ontológico está por definición más allá o más acá (como se quiera) de aquellas realidades problematizables, verificables, precisables. Por lo tanto, la única forma de acercarnos a este tipo de realidad es a través de un lenguaje analógico, metafórico que se construye más que a partir de definiciones y sentencias, a través de sucesivos acercamientos que nunca agotan el tema de que se trata. «Un misterio es un problema que avanza sobre sus propios datos, que los invade, y que se rebasa por eso mismo como simple problema» (Marcel, 1987: 38)².

2 Marcel usa casi indistintamente la noción misterio a secas y misterio ontológico. Al parecer, la noción misterio ontológico tiene una carga metafísica más fuerte y de algún modo describe la zona en que todo misterio acontece. En su Diario Metafísico propone la identificación: «Coincidencia de lo misterioso y lo ontológico» (Marcel, 1969: 124). 
La dificultad con que nos encontramos al reflexionar sobre lo que es el misterio estriba en que precisamente en este esfuerzo por desentrañar lo que él implica lo desvirtuemos llevándolo al nivel de problema: «Vemos inmediatamente que no se puede trazar una línea demarcatoria entre problema y misterio. Pues un misterio colocado ante la reflexión tiende inevitablemente a degradarse en problema» (Marcel, 1987: 38). Para ilustrar esta dificultad, Marcel nos ofrece lo que se sucede con el misterio del mal: «El mal puramente comprobado o contemplado deja de ser el mal sufrido: simplemente, deja de ser el mal. En realidad sólo lo capto como mal en la medida en que me atañe, es decir, en que estoy implicado en él) (Marcel, 1987: 39).

Otra de las formas que Marcel utiliza para nombrar al misterio es mediante la noción de lo metaproblemático. Se refiere a lo mismo, pero en vez de ser una noción positiva, hace alusión al misterio a partir de lo que no es o de lo que trasciende. El misterio es aquello que va más allá de lo problemático: lo metaproblemático. Usando esta terminología, Marcel se pregunta por el status ontológico de lo metaproblemático, por su carácter de realidad. ¿El misterio o lo metaproblemático no se podría mezclar acaso con las más ingenuas ilusiones y supersticiones? ¿Su carácter de irreductibilidad a la experiencia verificadora no lo vuelve en un peligroso elemento frente al cual la razón no tiene cómo parapetarse? Sin duda estas objeciones, siendo legítimas, nuevamente nos colocan en un plano donde lo metaproblemático se nos escapa en su ser, pues intentan llevarlo al ámbito de la comprobación, campo que le es ajeno. Marcel, en todo caso, no duda de la realidad de lo metaproblemático:

Pensar, o más exactamente, afirmar lo meta-problemático es afirmarlo como indudablemente real, como algo de lo cual no puedo dudar sin contradicción. Estamos aquí en una zona en la que ya no es posible disociar la idea misma y la certeza o el índice de certeza que la afecta. Pues esta idea es certeza, es garantía de sí; en esta medida es otra cosa y más que una idea (Marcel, 1987: 43-44).

Hasta aquí hemos intentado mostrar la primera tesis de este trabajo, a saber, cómo Marcel partiendo de una fenomenología, pasa a una metafísica de la existencia humana. Hemos ilustrado este punto recurriendo a las categorías de exigencia y misterio ontológico. Ahora es tiempo de pasar al segundo propósito de este artículo: mostrar algunos elementos de esta metafísica de la existencia humana. Este propósito ya está parcialmente logrado con la noción de misterio ontológico. Pero esta noción de algún modo nos muestra una esfera que va más allá de lo empírico y verificable sin decirnos positivamente qué podemos afirmar 
sobre aquello que fundamenta nuestra existencia. Las nociones de ser encarnado y de participación nos ayudarán a caracterizar a esta metafísica.

\section{E1 ser encarnado}

El punto de partida de la reflexión metafísica marceliana es el misterio del ser encarnado. Aquí se enfrenta frontalmente a Descartes. Contrapondrá al cogito como hecho central sobre el que se edifica el pensamiento de este último, la encarnación como dato central de la metafísica. El núcleo de esta polémica gira en torno a la concepción de existencia que maneja Marcel. La principal crítica que le hace a Descartes es el hecho de haber puesto entre paréntesis la existencia. Para Marcel en la existencia no hay nada que sea problemático ${ }^{3}$. El hecho de dudar de ella es contradictorio, pues se parte de una idea de existencia y luego se le aplica a eso que en el caso de Descartes soy yo mismo. Sin embargo, esa idea, ¿de dónde se origina? La única manera de hacerse una idea concreta de la existencia es partiendo de un esto que existe con toda seguridad. Pues bien, al poner Descartes en duda toda existencia, su propia idea de existencia se esfuma, pasando a ser una pseudoidea «que no se trae ninguna carta de crédito» (Marcel, 1956: 310).

Por otro lado, esa idea o pseudoidea puede ser utilizada sólo a condición de hacer una dualidad entre la existencia y el existente. Sin embargo, la existencia o la inexistencia, con mayor razón, no es un predicado, como definitivamente lo demostró Kant. Así se ve que esta ruptura entre la idea de existencia y el existente, es algo sólo permitido por la estructura de nuestro lenguaje, pero existencia y cosa existente para Marcel no pueden disociarse. Por el contario, estamos en presencia de una «síntesis indefectible, real o no, y en la cual no puede hacer mella la duda». La única manera de obrar aquí y realizar tal separación es obrar por «decreto», negando lo indubitable de la existencia, el «úndice existencial». La pregunta por mi existencia, para ser lógicamente coherente, según lo que hemos dicho, presupone un «mundo existente» (Marcel, 1956: 320). En todo caso, nuestro autor no propone a cambio una certeza apodíctica del yo:

[La existencia] cuya primacía se impone reconocer a nuestro juicio - y eso por un acto de verdadera bumildad espiritual-, esa existencia que se funde

\footnotetext{
3 Las ideas que desarrollaremos en este punto están recogidas en el artículo «Existencia y Objetividad» (Marcel, 1956: 310-311), que está publicado como parte de la edición castellana que utilizamos del Journal Métaphysique.
} 
con lo existente, no puede afirmarse de ninguna cosa particular y designable, ni siquiera del yo; y nunca se usará de bastante prudencia en la elección de las formulas destinadas a traducir lo que es menos una inmanencia abstracta que una presencia efectiva (Marcel, 1956: 320-321).

Con esto Marcel quiere plantear la existencia como un indudable que tiñe toda mi experiencia, pero, por lo mismo, no es acotable a un esto o a un aquello. Se trata de una presencia absoluta. Como consecuencia del cuestionamiento de la existencia que hace Descartes, para Marcel se pierde el dato metafísico central que es el dato de la encarnación, que siempre se refiere a tener un cuerpo que es sentido como mi cuerpo. $\mathrm{Al}$ perderse este dato y desconocer la fuerza de que se trata del mí, de la posesividad, el pensamiento cartesiano se construye sobre la base de una certeza racional universal, perdiendo la existencia sus rasgos concretos, personales, trágicos. Esto lleva a un tipo de pensamiento que pretende la universalidad absoluta, accesible a cualquier sujeto bajo ciertas condiciones. La reflexión marceliana, en cambio, comprometería al ser mismo que la realiza, pues en cada afirmación o negación que haga, es su misma existencia la que cae bajo el influjo de sus conclusiones, con lo cual volvemos a la distinción clave entre problema y misterio:

Y sin embargo, yo, que formulo este problema, debería poder mantenerme fuera -más acá o más allá- de ese mismo problema que formulo. En realidad está claro que no ocurre así; la reflexión me muestra que este problema invade, de alguna manera, de modo inevitable, ese proscenium teóricamente preservado. Sólo mediante una ficción el idealismo, en su forma tradicional, intenta mantener al margen del ser una conciencia que lo afirme o que lo niegue (Marcel, 1987: 33).

Sin embargo, por otro lado, también Descartes tuvo una inquietud por la existencia individual. De hecho su reflexión parte preguntándose por ella. Pero al encontrar en el cogito la certeza de su existencia, su pensamiento pierde el carácter concreto para elevarse en una abstracción impersonal:

Contrariamente a la idea que ha de presentarse aquí de modo natural, pienso que en este plano el cogito no puede prestarnos ayuda alguna. No obstante lo que Descartes haya podido pensar de ello, si él nos pone en posesión de algo indudable, este algo concierne sólo al sujeto epistemológico como órgano de un conocimiento objetivo. El cogito, he escrito en otra parte, guarda el umbral de lo universalmente válido, y eso es todo; la prueba de ello está en la indeterminación acerca del yo (Marcel, 1987: 33-34). 
Este intento cartesiano de establecer un «sujeto epistemológico como órgano de un conocimiento objetivo» tiene en su base a un dualismo criticado por Marcel: la «disociación entre lo intelectual y lo vital» (Marcel, 1987: 34). Si queremos pensar los problemas metafísicos es fundamental restablecer esta unidad:

Es cierto que es legítimo hacer distinciones jerárquicas en el seno de un ser vivo que piensa y se esfuerza por pensarse; pero el problema ontológico se plantea más allá de esas distinciones y para ese ser tomado en su unidad total (Marcel, 1987: 35).

Finalmente, Marcel reprocha a Descartes el plantear a la conciencia como un «círculo luminoso alrededor del cual no habría más que tinieblas» (Marcel 1969: 18). Es decir, critica la pretensión de transparencia de la conciencia. Para él la conciencia no es transparente para sí misma, sino al contrario «la sombra está al centro» (Marcel 1969:18). Esta «ocultación de la conciencia» se produce por «algo que no me es dado» (Marcel 1969: 134). Marcel plantea que en el centro del yo hay un misterio, que finalmente lo llevará a plantear que ese ser que es mi ser es un ser participado.

\section{La encarnación, dato central de la metafísica}

Para Marcel la encarnación se presenta como el dato central de la metafísica. La encarnación es la «situación de un ser que se presenta como ligado a un cuerpo» (Marcel, 1969: 15). La reflexión primera, aquella propia de las ciencias, tiende a desconocer esa posesividad, a «romper el frágil lazo significado por la palabra 'mío'» (Marcel, 1953: 95). Sin embargo, para nuestro autor, este hecho radical es el punto de partida y fundamento de toda objetividad y de todo conocimiento.

Para Marcel me encuentro desde siempre con un cuerpo que es sentido como mío. Esta posesividad radical me permite, de un modo misterioso, al mismo tiempo que «hablar sobre mi cuerpo» - con lo cual puedo establecer cierta distancia con él一, sentir que ese cuerpo es una parte esencial de mi ser, tan esencial, que cualquier ataque sobre él lo sentiré como un ataque sobre mi persona. En esto consiste el misterio del ser encarnado, misterio que me hace sentir mi cuerpo de este modo ambiguo.

¿Cómo describir este lazo que tengo con mi cuerpo? Aquí Marcel de partida descarta cualquier interpretación dualista. En términos fenomenológicos quizás la expresión más adecuada es decir que se trata 
de $m i$ cuerpo, con toda la ambigüedad que el mi presenta. Sin embargo, para nuestro autor, más allá de cualquier posesión, «hay un núcleo sentido y ese núcleo no es otra cosa que la experiencia -irreductible a términos intelectuales- del lazo por el cual el cuerpo es mío» (Marcel 1953: 99). Es decir, esta posesividad es ante todo una experiencia que más que ser descrita, debe ser «aludida o evocada» (Marcel 1953: 95). Este misterioso lazo se presenta de modo tan radical, que me hace imposible saber qué será de mí cuando ese vinculum se haya roto con la experiencia de la muerte (Marcel, 1953: 102). El cuerpo, en tanto experiencia radical y primera de posesividad, pasa a ser fundamento de toda experiencia de posesión: «Mis posesiones, en cuanto me apego a ellas, se presentan como complementos de mi cuerpo», de tal modo que «tener, en el sentido preciso de la palabra, debe pensarse en analogía con la unidad sui generis que constituye mi cuerpo en tanto mío» (Marcel, 1953: 100).

Sin embargo, esta relación estrecha, esencial, tiene siempre el riesgo de ser desnaturalizada al objetivarla, al «ponerla delante de mí», olvidando que el vinculum es ante todo algo «sentido», inobjetivable:

Sólo es legítimo decir "soy mi cuerpo" cuando se reconoce que el cuerpo no es asimilable a un objeto, o a una cosa. Mientras mantengo con él cierto tipo de relación (esta palabra no es perfectamente adecuada) que no se deja objetivar, puedo, afirmarme como idéntico a mi cuerpo, y aun la palabra "objetividad" es inadecuada, por cuanto es aplicable a un mundo de cosas y de abstracciones que la encarnación trasciende inevitablemente (Marcel, 1953: 102).

Marcel al usar la palabra «encarnación» está consciente de los equívocos a que tal uso puede dar cabida, especialmente al ser asimilada naturalmente al misterio cristiano. No obstante, es la manera más adecuada que encuentra para designar la situación «de un ser ligado esencialmente y no accidentalmente a su cuerpo» (Marcel, 1953: 102). Esta relación esencial, como venimos diciendo, es experimentada ante todo como un sentir, «un sentir mi cuerpo». De ese modo, este hecho de tener un cuerpo que es $m i$ cuerpo, pasa a ser también fundamento de todo sentir, teniendo mi cuerpo «prioridad absoluta con respecto a todo lo que puedo sentir» (Marcel, 1953: 103). En este punto, se evita cualquier interpretación del cuerpo que lo asimile a un instrumento a través del cual yo sentiría, pues el instrumento «que es una prolongación del cuerpo tiene siempre una comunidad de naturaleza con el cuerpo, ya que ambos son entidades prolongadas», por lo que nos veríamos obligados a «decir que el yo que usa el cuerpo como una extensión suya 
es él mismo corporal», pero «si lo es, es un instrumento de alguna otra cosa, y así in infinitum» (Gallagher, 1968: 49).

Lejos de eso, el sentir es una experiencia primaria inobjetivable que no se deja explicar por algún tipo de consideración posterior al ser ella misma fundamento de toda consideración, pues esta experiencia de la encarnación es el modo privilegiado como «estoy en el mundo»: «debemos reconocer la necesidad de hacer intervenir lo que llamaría un inmediato no mediatizable que está en la raíz misma de la existencia» (Marcel, 1953: 109).

Ese inmediato no mediatizable que es mi ser encarnado, hace las veces de un existencial indubitable y como tal, es el punto de partida de toda reflexión y de toda experiencia del mundo. El cuerpo es el mediador absoluto entre yo y el mundo. Esta forma «corporal» de «ser en el mundo», condiciona en forma absoluta mi "percibir el mundo», en la medida que mi cuerpo, en tanto mío y «presencia sólida y globalmente experimentada» (Marcel, 1953: 221) en cuanto «espesor vivido», me lleva a conferir a las otras cosas, en la medida que son evocadas por mí como existentes, un espesor de un orden análogo al que le confiero a mi cuerpo. Es decir, en ese sentido, podemos afirmar también que el cuerpo será el fundamento de todo juicio de existencia: «Toda existencia se construye para mí sobre el tipo y en la prolongación de la de mi cuerpo» (Marcel, 1956: 267).

La encarnación, en el pensamiento de Marcel, se presenta como una clave interpretativa de toda su filosofía. No entraremos aquí a demostrarlo, pero sí quisiéramos ofrecer algunas reflexiones en torno a la cuestión. En primer lugar, a través de la encarnación, como lo hemos insinuado, se pretende poner fin a toda interpretación dualista materiaespíritu, alma-cuerpo. Sin desconocer estas polaridades, de modo de no caer en un materialismo o en un espiritualismo, Marcel reconoce que en estos puntos se da una unidad indisoluble y misteriosa. De esta forma se ilumina bastante, por ejemplo, el tema del espíritu. A ese respecto, consecuente con esta visión, Marcel señala que «el espíritu sólo se constituye a condición de encarnarse» (Marcel, 1953: 184). Relacionado con esto, Marcel planteará la posibilidad de superar las aporías planteadas por el idealismo y el materialismo. Ellos tienden a desconocer al cuerpo, en el caso del primero, y al espíritu, en el caso del segundo: «Bien entendido, lo que es común aquí al idealismo y al materialismo es la repulsa radical que oponen al dato básico que constituye la encarnación» (Marcel, 1959: 109).

Otra de las perspectivas de la encarnación, está en la posibilidad de superar en forma categórica el dualismo sujeto-objeto. En ella se presenta superada tal dualidad: «De este cuerpo no puedo decir ni que es 
yo, ni que no es yo, ni que es para mí (objeto). De entrada la oposición sujeto-objeto se halla trascendida» (Marcel, 1969: 15). Desde el momento en que la encarnación «me lleva a conferir a las otras cosas, en la medida que son evocadas por mí como existentes, un espesor de un orden análogo al que le confiero a mi cuerpo» (Marcel, 1953: 221), también puedo trascender la oposición sujeto-objeto en mi experiencia con el mundo ${ }^{4}$.

Estas son algunas de las consecuencias planteadas por lo que Marcel llama la «exigencia de encarnación». Sin embargo, nos queda pendiente quizás la más importante y que fundamenta y explica las expuestas en esta parte. Ésta dice relación con el hecho de que la encarnación es el fundamento de la participación, noción clave para nuestro autor, tema que desarrollaremos a continuación.

\section{La participación}

Marcel cree que este modo peculiar de «abrirme al mundo» y de «ser en el mundo» (Marcel, 1953: 189), que es a partir de mi ser encarnado, testimonia de modo privilegiado la esencia de mi relación con el mundo que es a través de la participación. En la obra El Misterio del Ser se nos describe en qué consiste esto de la participación. Marcel ve en el hombre algo que él llama la «voluntad de participación». Se trata de cierta «disposición interior, no representable», que nos lleva a desear «tomar parte» en una empresa, a desear sentirnos parte, más allá de los beneficios o costos que ello traiga, como se puede observar en la participación de sujetos en ciertas empresas dolorosas y costosas, tales como las distintas «resistencias» a las ocupaciones ${ }^{5}$, por ejemplo (Marcel, 1953: 114).

Sin embargo, debemos ir más allá y reconocer que esta voluntad de participación sin la cual «la experiencia humana más irrecusable se torna ininteligible» (Marcel, 1953: 114), no sólo se expresa como una disposición interior o un deseo de «tomar parte», sino que define los vínculos primarios y radicales que tenemos con la realidad, como lo

\footnotetext{
4 «Marcel llega a decir que la unión entre alma y universo es de la misma naturaleza que la existe entre alma y cuerpo, queriendo decir con esto que yo no soy más separable del mundo de lo que lo soy de mi propio cuerpo» (Gallagher, 1968: 51).

5 El tema de la resistencia (la francesa en la segunda guerra mundial) produjo un fuerte impacto en Marcel: «En lo que se refiere a mi evolución interior, cobra importancia fundamental toda la serie de problemas que traía consigo la "resistencia" francesa, por un lado, y los crímenes de los "nazis" y de los soviets, por otro (...)» (Marcel, 1967: 12).
} 
podemos apreciar al ver el lazo «que une al campesino a la tierra, o al marinero al mar» (Marcel, 1953: 113). Se trata de un lazo constitutivo no objetivable, donde incluso la distinción sujeto-objeto pierde sentido. En la participación, el conocimiento objetivo pierde su sustancia, puesto que «cuanto más participo efectivamente en el ser menos capacidad tengo de saber o decir en qué participo» (Marcel, 1959: 71). El misterio de la participación de alguna manera expresa el lazo que me une con lo real. Desde el momento en que negamos la participación, estamos negando al mismo tiempo nuestros lazos con la realidad (Marcel, 1954: 156).

Para Marcel, el sentir es uno de los modos privilegiados que toma la participación, reconociendo que dicha experiencia excede considerablemente los límites del sentir (Marcel, 1953: 122). Sin embargo, podemos agregar nosotros, que desde el momento en que el sentir fundamenta y expresa esa relación esencial con mi cuerpo, cuerpo que es la manera que estoy en el mundo, el sentir se transforma así en el fundamento de toda participación ${ }^{6}$.

La participación, que para Marcel no es otra cosa que la manera de expresar la manera que en que estoy inserto y envuelto radicalmente en el misterio ontológico, encuentra su expresión y actualización más concreta en la intersubjetividad. A continuación mostraremos algunos de los principales rasgos de la intersubjetividad, para finalmente mostrar, a partir de esos rasgos, como la participación se da ante todo en ella.

Cuando nos referimos al misterio ontológico dijimos que éste tiene que ver con una experiencia, con una presencia que viene a llenar una necesidad de sentido, de ser. Justamente debido a estos rasgos del misterio ontológico, la participación en él no se puede producir sino a partir de una «plenitud vivida», de una experiencia de sentido contundente. Para Marcel tal experiencia está mediada necesariamente por la intersubjetividad, pues al tratarse de una experiencia de «plenitud vivida», tal carácter no le puede venir de «mi experiencia considerada en su aspecto privativo» (Marcel, 1953: 207), sino que requiere necesariamente vivirse en la dinámica del $\mathrm{con}^{7}$.

De ese modo la metafísica marceliana - como ya lo hemos señalado-, se distanciará radicalmente de la cartesiana: «una toma de posición semejante, de inmediato pone de relieve el carácter esencialmente anticartesiano de la metafísica hacia la cual vamos a tener que

\footnotetext{
6 De un modo aún más concluyente lo afirma Gallagher (1968: 53): «La sensación, no es una recepción, sino una participación inmediata en el ser. Es la operación que actualiza mi encarnación en el mundo».

Marcel le dará mucha importancia a la proposición «con», en cuanto expresa fenomenológicamente en forma acabada la experiencia de la intersubjetividad.
} 
orientarnos. No basta decir que es una metafísica del ser: es una metafísica del somos, por oposición a la metafísica del yo pienso» (Marcel, 1953: 207).

La primera dificultad con que nos encontramos al analizar la intersubjetividad, es que ella no es algo que se pueda «comprobar», pues lo comprobable son los hechos, algo que se me $d a$, pero precisamente la intersubjetividad no es algo que se me $d a$, puesto que estoy implicado en ella, incluso más, es la condición "para que algo me sea dado» (Marcel, 1953: 208). La única forma de acercarnos al nexo intersubjetivo es reconociéndolo como aquello en lo cual ya estamos. Aunque intentemos traducirlo y expresarlo en un enunciado, nos encontramos con la dificultad de que la intersubjetividad es la condición misma de todo enunciado (Marcel, 1953: 209). Marcel, que siente un especial afecto por la música y por sus metáforas, señala que la intersubjetividad se asemeja a aquél universo en que me sumerjo cuando improviso en piano, aquel mundo de donde extrae sus melodías el músico (Marcel, 1953: 212).

Resumiendo podríamos decir que si bien para Marcel el misterio ontológico tiene una precedencia con respecto a la intersubjetividad, en la medida en que ésta está «envuelta», "sumergida» en el misterio, debemos afirmar que para nuestro autor el misterio ontológico acontece, se realiza y se constituye en la intersubjetividad. Es tan fuerte el lazo entre estas dos nociones, que «el espesor del ser se adelgaza en la medida en que el ego pretende atribuirse una posición central en la economía del conocimiento» (Marcel, 1953: 213). Podríamos decir que para Marcel no hay posible aproximación concreta al ser sino a través de la relación auténtica: «(...) no me preocupo por el ser, sino en la medida en que tomo conciencia más o menos indistinta de la unidad subyacente que me une a otros seres cuya realidad presiento» (Marcel, 1953: 214). Al mismo tiempo, toda comunidad que no se arraigue profundamente en lo ontológico, termina por disolver aquello que la constituye: los lazos reales humanos (Marcel, 1953: 213). Aquí pareciera estar identificando Marcel al misterio ontológico con aquello que nos une a los demás seres.

Para comprender mejor la fuerza que Marcel le da a la intersubjetividad, es necesario que nos concentremos en otro aspecto de gran importancia: el hecho de que cada uno de nosotros lleva en sí el sello de la intersubjetividad. Marcel afirma en forma categórica nuestra dimensión intersubjetiva: «Pero tenemos que penetrar más hondo y reconocer que la intersubjetividad afecta al sujeto mismo, que lo subjetivo en su estructura propia es ya profundamente intersubjetivo» (Marcel, 1953: 167).

Este hecho tiene importantes consecuencias que hacen que esta filosofía sea un esfuerzo contundente por superar el solipsismo 
moderno. De hecho, el propio yo, se constituye esencialmente en relación con otros en el reconocimiento que encuentra en ellos:

Desde muy temprano se opera en el ser humano una conjunción, una articulación entre esa conciencia de existir que, sin duda, no tenemos razón valedera para negar al animal, y la pretensión de hacerse reconocer por el otro - ese testigo, esa ayuda, o ese rival, o ese adversario que, a despecho de lo que se haya podido decir, es parte integrante de mí mismo, pero cuya posición puede variar casi indefinidamente en mi campo de conciencia (Marcel, 1954: 17-18).

A propósito de esta constatación, Marcel logra vincular de un modo novedoso la experiencia personal con la ajena: «Llegaré así a un extraño y maravilloso descubrimiento: a medida que me elevo a una percepción verdaderamente concreta de mi propia experiencia, estoy en condiciones de acceder a una comprensión efectiva del otro, de la experiencia del otro» (Marcel, 1953: 206).

De ese modo, la experiencia personal aparece como un lugar privilegiado de comprensión de la experiencia ajena, con lo que se rompe cualquier riesgo de concebir a un sujeto encerrado en su propio mundo interior. Por otro lado, la experiencia ajena nos permite comprender y desarrollar la propia, pues «sólo a partir de los otros podemos comprendernos» y fundar un auténtico amor de sí que no caiga en un egocentrismo (Marcel, 1953: 207).

Esto nos abre a una paradoja que quiebra los esquemas moralizantes que tienden a ver en la preocupación por sí mismo un riesgo para la auténtica comprensión y preocupación por los demás y la preocupación por los demás como un riesgo para el sujeto. En el plano de la intersubjetividad, que para Marcel será el del amor, estas distinciones entre el otro y el yo como realidades contrapuestas pierden sentido. Contrario a lo que se suele sostener - como corolario a lo dicho en el párrafo anterior-, la comprensión concreta de sí no es siempre egocéntrica. Es más, el egocentrismo, lejos de ser una intelección o comprensión desmesurada de sí, para nuestro autor «es posible en un ser que no es efectivamente dueño de su experiencia, que no la ha asimilado verdaderamente» (Marcel, 1953: 207). Es decir, el egocéntrico, paradójicamente, está descentrado de sí mismo, lo que lo hace cegarse y cerrarse a los demás, pues cada uno, en sus profundidades, tiene el sello de la intersubjetividad, por lo que una cerrazón a la propia experiencia conlleva una cerrazón a la ajena y, al mismo tiempo, una cerrazón a la ajena implica una cerrazón a la propia, pues «mi experiencia está en 
comunicación real con las otras experiencias y no puede separarse de ellas sin separarse de sí misma» (Marcel, 1953: 207).

Como hemos intentado mostrar, la participación es la manera que describe nuestra manera de estar insertos en el mundo y en el misterio ontológico. Este misterio, como señalamos, se realiza y concreta en la intersubjetividad, que lejos de ser un lazo tenue o un sentimiento vago, es aquel dominio «donde la vida está afectada con el signo con» (Marcel, 1953: 164), aquella comunión que permite la comunicación real y la posibilidad misma que pueda reconocerme en mi mismidad y no sentirme como un extraño (Marcel, 1953: 186).

Por lo tanto, desde el momento en que la noción de participación está referida esencialmente al misterio ontológico y partiendo de la base de que el misterio acontece y se concreta en la intersubjetividad, tenemos que la participación se plasmará ante todo en la intersubjetividad, en el con, en el togetherness. Los individuos se sentirán «participando» en el misterio, en la medida que «llegan a conocerse individualmente y a reconocerse en la singularidad de su ser y su destino» (Marcel, 1953: 165). Esta participación concreta es lo que funda la posibilidad de «aproximarnos ontológicamente, es decir, en tanto seres» (Marcel, 1953: 163). La participación en la intersubjetividad se dará como un movimiento paradójico donde simultáneamente al profundizar en mi experiencia profundizo en la ajena y donde al abrirme a la experiencia ajena me abro a la mía. Esta paradoja que supera cualquier visión cosista de la relación personal que la pudiera asimilar a un esquema sujetoobjeto, se funda, insistimos, en el hecho de que la intersubjetividad es una dimensión de cada uno.

Finalmente, tenemos que afirmar que si bien la intersubjetividad se «anida» en lo profundo de nuestro ser, no es un factum que me determine, sino al contrario, acontece en cada uno como una llamada a la libertad. De tal modo que cada uno puede vivir en consecuencia con su dimensión intersubjetiva y de ese modo participar plenamente en la unión intersubjetiva o bien puede cerrarse a ella negándola. Aquí Marcel, como en muchas otras partes, se acerca al lenguaje religioso, al plantear que esta cerrazón a la intersubjetividad corresponde a lo que llamamos pecado:

Que considere mi alma como una perla que debo extraer de las profundidades, como estatua para modelar, como un jardín para cultivar -una multitud de metáforas semejantes pueden inventarse-, en todas esas perspectivas corro el riesgo de desconocer los derechos superiores de la intersubjetividad o, en un lenguaje más sencillo y más convencional, que 
sin duda será conveniente emplear, de pecar contra el amor (Marcel, 1953: 228).

A decir verdad, la analogía parece bastante perfecta y ayuda a entender el contenido de algunas de las afirmaciones que hace la teología respecto al pecado. Al interpretarlo desde esta óptica filosófica, podemos entender el por qué el pecado es ante todo contra el amor (que aquí es interpretado como apertura y participación en la intersubjetividad) y por qué para la teología todo pecado daña simultáneamente las relaciones con Dios, con el prójimo y consigo mismo. Desde el momento en que la intersubjetividad concreta las relaciones con lo trascendente (que en este lenguaje marceliano es llamado misterio ontológico), las relaciones con el prójimo y las con uno mismo (ya que lo «subjetivo en su estructura propia es ya profundamente intersubjetivo»), el cerrarse a ella conllevará un daño a esta triada de relaciones. Así también teológicamente esta analogía nos sirve para entender la imagen del infierno como soledad y del pecado como traición al propio ser.

\section{Conclusiones}

El acercamiento que hace Marcel a la metafísica, como dijimos, comienza con la experiencia del ser de cada hombre. El ser es aquello que completa la necesidad de sentido, de plenitud, incluso de vida que todos tenemos. Veíamos cómo esa afirmación fenomenológica pasa en Marcel a ser metafísica, al afirmar que esa necesidad, la exigencia del ser, no es un mero anhelo subjetivo, sino un misterio en el cual estamos inmersos. De esta manera, hemos tratado de demostrar la primera tesis de este trabajo: la tesis de que Marcel plantea una metafísica a partir de una fenomenología.

En segundo lugar, a través de las nociones de misterio ontológico, de encarnación y participación, he tratado de esbozar algunos de los rasgos de la metafísica de la existencia humana de Marcel. El punto de partida de esta reflexión metafísica es el ser encarnado. Uno de los rasgos propios del dato de la encarnación es su ambigüedad, la que se manifiesta en el hecho de que al mismo tiempo que tenemos un cuerpo y lo sentimos como nuestro, no nos identificamos plenamente con él. A partir de ese hecho, Marcel expresa que no somos sólo cuerpos, sino que hay un ser que nos anima, es decir, que somos seres encarnados. Ahí tenemos un primer modo de vinculación de la existencia personal con el 
misterio ontológico, puesto que ese ser que soy es el lugar donde el misterio acontece.

De un modo más definitivo, a través del misterio de la participación, se nos muestra de un modo contundente el nexo entre mi existencia concreta y el misterio ontológico. A través de mi ser encarnado, participo en el mundo, soy en el mundo. Esa misma participación se da en otros niveles, como en los deseos de sentirme parte de empresas mayores, de proyectos, etc. La intersubjetividad será otro nivel donde se verificará la participación, en la medida en que me inserto en una comunidad concreta. Todas estas participaciones testimonian y expresan una gran participación, que es mi participación en el misterio ontológico.

Aquí encontramos un vínculo clave. La participación viene a ser el modo en que se vincula la experiencia personal y el misterio ontológico. Esta participación en el misterio se da siempre, pues somos en el misterio, es lo que nos constituye y nos hace ser. Sin embargo, no siempre se actualiza plenamente en la persona. Si bien estamos inmersos en el misterio, depende de nosotros el que ese misterio acontezca de manera activa.

¿Podemos quedar satisfechos con esta metafísica marceliana? Si lo que esperamos de su metafísica es un sistema, sin duda quedaremos con gusto a poco. Pero si lo que buscamos es, a partir de la experiencia humana, plantear como posibilidad un misterio que nos trascienda y que fundamente nuestra existencia y las relaciones humanas, me parece que podemos sentirnos satisfechos. A partir de la noción de encarnación (que nos sitúa en el mundo desde nuestra experiencia de tener un cuerpo), de participación (que nos sitúa en una realidad que nos trasciende y en medio del misterio de las relaciones humanas), podemos esbozar una metafísica que de alguna manera sirva de contrapeso a una sociedad donde el ser humano se reduce a un mero haz de funciones. Si bien no estamos en condiciones de dar una definición concreta del misterio que nos envuelve, Marcel nos muestra que nuestra existencia se encuentra anclada en algo que la trasciende, que le da sentido y que permite que formemos auténtica comunidad, lugar concreto donde acontece el misterio.

\section{REFERENCIAS}

-Conill, J. (1988). El crepúsculo de la metafísica. Barcelona: Anthropos.

-Gallagher, K. (1966). La Filosofía de Gabriel Marcel. (A. Gutiérrez, Trad.) Madrid: Razón y Fe. 
-Jaspers, K (2006). La filosofía: desde el punto de vista de la existencia. (J. Gaos, Trad.) México: Fondo de Cultura Económica.

-Marcel, G. (1953). El Misterio del Ser. (M. E. Valenté, Trad.) Buenos Aires: Sudamericana.

-Marcel, G. (1954). Prolegómenos para una metafísica de la Esperanza. (M. E. Valenté, Trad.) Buenos Aires: Editorial Nova.

-Marcel, G. (1956). Diario Metafísico (1914-1923). (J. Rovira, Trad.) Buenos Aires: Losada.

-Marcel, G. (1959). Filosofía Concreta. (A. Gil Novales, Trad.) Madrid: Revista de Occidente.

-Marcel, G. (1967). Dos discursos y un prólogo autobiográfico. Barcelona: Herder.

-Marcel, G. (1969). Diario Metafísico (1928-1933). (F. del Hoyo, Trad.) Madrid: Guadarrama.

-Marcel, G. (1987). Aproximación al misterio del Ser. Posición y aproximaciones concretas al misterio ontológico. (J. L. Cañas, Trad.) Madrid: Encuentro.

Sumario: Introducción; 1. La situación del hombre contemporáneo; 2. El hombre frente al misterio; 3. El misterio ontológico; 4. El ser encarnado; 5. La encarnación, dato central de la metafísica; 6. La participación; Conclusiones; Referencias. 